\title{
NACIONALIDADE E CIDADANIA: NECESSARIAMENTE VINCULADAS?
}

\section{Samuel Aguiar da Cunha*}

Resumo: Por ser assunto relevante, o artigo discute, abordando por método hipotéticodedutivo e a partir de procedimento histórico-comparativo por meio de documentação indireta (literatura especializada), se a nacionalidade é causa necessária para o exercício da cidadania. Após verificação no transcurso do tempo e da conceituação de ambos os institutos no momento presente, pode-se constatar que a nacionalidade e a cidadania, ainda que muito próximas em sua origem, dizem respeito a implicações bastante distintas - a saber, aquela, como vínculo do Estado para com o indivíduo, e essa, como potencialidade do indivíduo frente à coletividade (especialmente o Estado).

Palavras-chave: nacionalidade; cidadania; nação; Estado; direito

\section{NATIONALITY AND CITIZENSHIP: NECESSARILY LINKED?}

Abstract: As it is a relevant subject, the article discusses, using a hypothetical-deductive method and from a historical-comparative procedure through indirect documentation (specialized literature), whether nationality is a necessary cause for the exercise of citizenship. After checking over time and the conceptualization of both institutes at the present time, it can be seen that nationality and citizenship, although very close in origin, have quite different implications - namely, that as a bond from the State to the individual, and this, as the individual's potentiality vis-à-vis the collectivity (especially the State).

Keywords: nationality; citizenship; nation; State; rights

\section{INTRODUÇÃO}

O estudo, conceituação e delimitação da nacionalidade (e de atributos que eventualmente se entendam correlatos) se reflete em várias matérias da ciência jurídica, mas de modo muito peculiar nos campos do Direito Constitucional e do Direito Internacional. Por ser a Constituição o documento maior a estabelecer a relação jurídica do Estado, é natural que nela se discutam os indivíduos legitimados a interferir na vida do Estado, i.e., o povo para quem a estrutura estatal se monta e se justifica. Dessa forma, não é exagero dizer que a importância é máxima, explicitando quem são os atores dessa esfera interna.

Já no campo internacional, conhecer a qual país determinada pessoa se encontra subordinada nacionalmente interfere precipuamente nas condições em que seus direitos

\footnotetext{
* Bacharel (Centro Universitário Ritter dos Reis), Mestre (Universidade Regional do Alto Uruguai e das Missões) e Doutorando em Direito (Universidade La Salle); Advogado. Endereço: Rua Coronel Bordini, 1003, bairro Auxiliadora, CEP 90440-001, Porto Alegre, RS. E-mail: samuel@aguiardacunha.com.br. Lattes: http://lattes.cnpq.br/0889095514195709. ORCID: http://orcid.org/0000-0001-6549-5233.
} 
serão processados, sendo, portanto, o sub qua lege vivis o elemento de conexão entre duas ou mais nações para dirimir dúvidas e resolver conflitos.

O presente artigo, então, intenciona questionar uma afirmação tratada de maneira assente pelos juristas no ramo do Direito Público: seria a cidadania um atributo da nacionalidade? Com isso, pretende-se verificar em recorte da literatura especializada se cidadania e nacionalidade são institutos respectivamente antecedente e consequente ou se guardam outra relação, causal ou não.

Para se cumprir essa tarefa, faz-se emprego do método hipotético-dedutivo, sob viés histórico-comparativo a partir de documentação indireta, tratando, num primeiro instante, do surgimento histórico dos dois institutos para, em seguimento, abordar a cada um segundo seus conceitos e peculiaridades, trazendo, ao final, suas correlações e respondendo ao problema suscitado.

\section{SURGIMENTO DA CIDADANIA E DA NACIONALIDADE}

De todas as interações a que o indivíduo está submetido, as circunstâncias forçam a ver como primeira (seja no momento em que se estabelece, seja na primazia que exerce, em razão de toda a carga subjetiva que imprime) aquela estabelecida no seio familiar entre os seus membros. Inegável é a influência do conjunto de pessoas que partilham do mesmo sangue, que comungam da mesma mesa e que carregam os mesmos valores, credos e tradições. Embora as muitas letras da ciência possam requerer, não são necessárias muitas elucubrações para constatar, a partir da experiência pessoal até o estabelecimento formal dos Estados, a relevância que esse vínculo representa.

Desde tempos imemoriais, o homem se mostra um ser gregário; essa agregação seja numa solidariedade mecânica, seja numa solidariedade orgânica, como postulara Durkheim (1999) - sempre se centrou num ponto comum, qual seja, a proximidade dos entes entre si, demonstrada na reciprocidade de reconhecimento dessa proximidade. Desse vínculo, aparente nas mais remotas reminiscências humanas, é que surgem as primeiras demonstrações de proteção grupal, resguardando-se os elementos que o compõem daqueles demais a que não se estabelecem vínculos que os aproxime.

Diante dos presentes axiomas, não parece forçoso correlacionar o vocábulo nação à ideia de nascer, palavra de mesma origem (FARIA, 1988, p. 353) - i.e., de poder ser visto o grupo nacional como uma evolução e grande consequência da extensão do núcleo da família 
- e, nisso, a História e a Biologia podem atestar com toda a precisão o surgimento e a permanência de grupos certos e determinados, com mesmas características fenotípicas (algumas só possíveis em condições extremamente específicas e restritas) e que mantêm hábitos culturais que desafiam o pensamento darwinista de tão longínquos que são.

Paulatinamente, o correr dos séculos vai apontando o desenvolvimento dessas famílias em verdadeiras nações, grupos étnicos bem distintos dos demais por diversos fatores (língua, religião, culinária etc.), que vão tendo suas estruturas de poder legitimadas aos poucos, surgindo, então e posteriormente, a figura moderna do Estado. A propósito, Dardeau de Carvalho (1950, p. 6) vê a formação estatal como nada mais senão a estrutura política adotada pela nação (ou grupo de nações), segundo seus interesses e imperiosidades em geral.

No mesmo compasso em que se identificam os pertencentes do grupo, excluem-se os que não o são: surgem dessa exclusão conceitual os "estranhos", ou seja, estrangeiros (extraneous), pessoas que não se assemelham ao grupo que os define, não guardando relações de proximidade prima facie (seja ela de caráter biológico/consanguíneo, seja de cariz étnico-cultural), e que, portanto, não merecem a proteção do grupo (e, dependendo dos hábitos que tal grupo apresentassem, conforme o cenário histórico em que viviam, poderiam sofrer até o expurgo total ${ }^{\dagger}$ ). Já em evolução à primeira ideia, Fustel de Coulanges (2008, p. 213-4, sem grifos no original) exprime a situação da primeva sociedade política grecoromana, associando sua situação junto à comunidade com seus hábitos religiosos:

Era reconhecido como cidadão todo aquele que tomava parte no culto da cidade, e
dessa participação lhe derivavam todos os seus direitos civis e políticos; [...] o
estrangeiro é aquele que não tem acesso ao culto [...]. Os deuses nacionais, que
só querem receber orações e oferendas dos cidadãos, repelem todo homem
estrangeiro: [...]

\begin{abstract}
${ }^{\dagger}$ Aqui se pode citar, a título de exemplo, o caso judaico clássico, em que a Divindade teria determinado enquanto faziam sua peregrinação do Egito à terra de Canaã: “"Quando o Senhor, o seu Deus, os fizer entrar na terra, para a qual vocês estão indo para dela tomarem posse, ele expulsará de diante de vocês muitas nações: os hititas, os girgaseus, os amorreus, os cananeus, os ferezeus, os heveus e os jebuseus. São sete nações maiores e mais fortes do que vocês; e quando o Senhor, o seu Deus, as tiver dado a vocês e vocês as tiverem derrotado, então vocês as destruirão totalmente. Não façam com elas tratado algum, e não tenham piedade delas. Não se casem com pessoas de lá. Não deem suas filhas aos filhos delas, nem tomem as filhas delas para seus filhos, pois elas desviariam seus filhos de seguir-me para servir a outros deuses e, por causa disso, a ira do Senhor se acenderia contra vocês e rapidamente os destruiria. Assim vocês tratarão essas nações: derrubem os seus altares, quebrem as suas colunas sagradas, cortem os seus postes sagrados e queimem os seus ídolos. Pois vocês são um povo santo para o Senhor, o seu Deus. O Senhor, o seu Deus, os escolheu dentre todos os povos da face da terra para ser o seu povo, o seu tesouro pessoal"” (Dt. VII, 1-6) (BÍBLIA, p. 140, sem grifos no original).
\end{abstract}


Tal afirmação não está descompassada do que já se expôs (COULANGES, 2008, p. 38-9, sem grifos no original):

[...] [na religião dos antigos] os seus deuses não aceitavam indistintamente a adoração de todos e quaisquer homens. [...]. Nessa religião primitiva, cada um dos deuses não podia ser adorado por mais de uma família. A religião era puramente doméstica. $[. .$.

$\mathrm{O}$ culto aos mortos não o podemos de modo algum aproximar daquele que os cristãos têm pelos santos. Uma das primeiras regras do culto aos mortos estava no fato de este só poder ser prestado aos mortos de cada família [que] pelo sangue lhes pertencia. [...] Acreditava-se que o morto só aceitava a oferenda quando esta lhe fosse prestada da mão dos seus; só queria o culto de seus descendentes. Por essa razão, a lei proibia o estrangeiro de se aproximar do túmulo. [...] A palavra pela qual os antigos designavam o culto dos mortos afigura-se-nos bastante elucidativa: os gregos diziam pratiázen, os latinos chamavam-lhe parentare. [...] O culto dos mortos representa verdadeiramente o culto dos antepassados. ${ }^{*}[\ldots]$

Se, pelo contrário, os sacrifícios sempre se realizavam segundo os ritos, e se os alimentos eram levados ao túmulo nos dias fixados, tínhamos então no antepassado um deus protetor. Hostil a todos os que não descendiam dele, repelindo-os de junto do seu túmulo, atacando-os com doenças quando dele se aproximavam, para os seus era sempre bom e compassivo.

Dessa forma, o laço consanguíneo (criando um dever que, posteriormente seria tido como juridicamente obrigatório) era o que aproximava os entes à coletividade. A dicotomização nascido-estranho foi mudando no correr dos anos, até mesmo acompanhando o crescimento das famílias, mas sempre mantendo a proximidade de uns e o distanciamento dos outros - o que pode expressar, sem grandes dificuldades, a visão da nação frente ao estrangeiro.

O sentimento helênico de participação no Estado desse modo se atrelava à pertença ao grupo; contudo, exigia dos que dela quisessem participar ativamente uma condição objetiva, qual seja, a capacidade de gerirem sem serem geridos, mantendo, outrossim, um vínculo de interdependência. Em outras palavras, a principal condição de participação política era a liberdade - que excluía de imediato estrangeiros, mulheres e escravos - que não olvida a necessidade de proximidade (DAL RI JÚNIOR, 2003, p. 26-7); cabe apontar, inobstante, que a cidade, para Aristóteles (2008, p. 11-5), era a sociedade formada de pequenos burgos (unidades familiares estendidas, formadas de homo galactiens), e a capacidade de se relacionarem é que faria com que os indivíduos viessem a se reconhecer membros do Estado, legando à posteridade a colocação: “ora, o que não consegue viver em

\footnotetext{
¥É de relevo a nota original contida nesse trecho, especialmente para verificar o paralelismo que a adoção da nacionalidade secundária (naturalização) causa: "Assim foi, pelo menos originariamente; depois, as cidades tiveram os seus heróis típicos e nacionais, como mais adiante veremos. Também estudaremos como a adoção criava parentesco fictício e dava o direito de honrar uma série de antepassados" (sem grifos no original).
} 
sociedade, ou que não necessita de nada porque se basta a si mesmo, não participa do Estado; é um bruto ou uma divindade".

Se na Grécia não foi possível cunhar a que acepção o termo cidadão trataria, "podese afirmar, com segurança, que foi Roma a primeira cidade-Estado a instituir o conceito jurídico de cidadania, ligando-o intimamente à noção de status civitatis" (DAL RI JÚNIOR, 2003, p. 29), isso porque foi pela previsão do direito romano que se atribuiu o status de cidadão a quem fosse membro de um clã romano. Tal percepção se dá justamente pelo fato da família anteceder ao Estado, fundando-o em consequência.

Não é sem turbações, diga-se, que a cidadania romana percorre seu tempo: da fase antiga à República, e dessa ao Império, o avanço gradual do domínio também avança na identificação dos indivíduos, concedendo-lhes mais e mais o status de cidadãos, i.e., mais grupos e pessoas foram atingindo esse patamar. Deve-se à Constitutio Antoniniana, em 212 $\mathrm{AD}$, o franqueio a todos para esse conjunto de direitos resumidos no civis romanus, sendo que, do que mais se poderia cultivar nessa situação, a liberdade (libertas) foi o valor fulcral (DAL RI JÚNIOR, 2003, p. 36) ${ }^{\S}$.

Posteriormente, com a igualdade dos cidadãos frente ao Estado romano, a igualdade dos crentes frente ao Deus cristão e o declínio dos Césares ante a expansão da religião do Nazareno, constata-se que, com a queda do Império e a invasão bárbara, formam-se novos reinos que, por costume, recebiam de seus subordinados o juramento de fidelidade (vassalaticum) e lhes davam, por ato do seu soberano, a proteção e o sustento requeridos (beneficium). Nessa manifestação medieval-feudal, posto que esvaziada de prerrogativas, mas cheia de deveres, pode-se dizer que a cidadania se viu mortalmente esvaziada de conteúdo (DAL RI JÚNIOR, 2003, p. 38-43); todavia, forte é a semelhança com o instituto da nacionalidade, se vista enquanto proteção por parte do poder organizado sobre determinada área territorial, para cuidado dos indivíduos que nele estão a fim de sustento dessa hiperestrutura mantenedora (SOUZA JÚNIOR, 2002, p. 29-40).

Fez-se necessário que gerações passassem para que a fruição de direitos pelo homem fosse algo que ultrapasse os domínios dos Estados. Ainda que importantes pensadores, tais quais Bodin ([1576] 1992), Hobbes ([1651] 1998), Pufendorf ([1672] 1703) e mesmo Rousseau ([1762] 1978) e Sièyes ([1789] 1986) hajam feito grandíssimas contribuições para

\footnotetext{
$\S$ Curiosamente, tal medida não intentava aumentar direitos propriamente, mas fortalecer o tesouro de um Império dilapidado pela insânia de seu imperador (LISSNER, 1985, p. 347).
} 
a mudança da concepção de cidadania, modificando seu eixo de uma verticalidade concedida a uma horizontalidade obtida, bem como sua direção, de uma descendência autoritária a uma ascendência legitimatória, é só em Immanuel Kant ([1795] 2010) que se pretende superar a soberania estatal para fugir à guerra e conquistar a paz aos cidadãos; contudo, mesmo sob a ideia de foedus pacificum, esteve a permanecer a atuação do Estado, que se aliança com os outros Estados para bem dos indivíduos, e que não é obrigado a oferecer aos estrangeiros muito mais que um direito de hospitalidade (p. 31-41). Entende Habermas (2007, p. 353-4), em contraponto e inserido em outro contexto histórico, que o fato de Kant propor uma solução que esteja em nível supraestatal já traz em si o dínamo para modificar o ponto nodal da soberania estatal:

[...] Com a passagem do direito das gentes, centrado em Estados, para o "direito de cidadãos do mundo" (Weltbürgerrecht), o espaço de ação dos atores estatais é circunscrito, sem que sua característica, enquanto "sujeitos de uma ordem jurídica que abarca o mundo", seja marginalizada pelos "sujeitos individuais do direito de cidadãos do mundo". Estados estruturados de forma republicana podem continuar sendo, ao lado dos "cidadãos do mundo" (Weltbürger), sujeitos de uma constituição mundial que, por sua vez, não possui núcleo estatal.

Para isso, entende ser imperioso "adaptar o conceito de soberania do Estado às novas formas de governar que se estendem para além do Estado nacional", uma vez que

[...] A constituição política tem como meta colocar tais sistemas [Estado, economia e sociedade civil] em forma com o auxílio do medium do direito e correlacioná-los entre si, de tal sorte que eles possam preencher suas funções de acordo com a medida de um suposto "bem comum". E a fim de fornecer uma contribuição para a maximização do bem comum, a constituição deve prevenir, lançando mão da capacidade estruturadora de uma ordem jurídica global, desenvolvimentos falhos de sistemas específicos.

Nesta linha, o poder organizacional do Estado deve garantir direito e liberdade, sem descarrilar para os lados do poder repressivo, da tutela paternalista ou da coerção normalizadora. A economia deve promover produtividade e bem-estar sem ferir os padrões da justiça distributiva (ela deve promover o maior número possível, mas sem prejudicar ninguém); e a sociedade civil deve engajar-se pela solidariedade de cidadãos independentes, sem descambar para o coletivismo ou para a integração coagida e sem provocar fragmentação ou polarização das visões de mundo. O bem comum, postulado, não está ameaçado apenas pelos "fracassos do Estado" (insegurança do direito e opressão), mas também por "fracassos do mercado" e pela evaporação da solidariedade. O caráter indeterminado do bem comum, que é questionado em sua natureza, é fruto da falta de equilíbrio entre essas duas grandezas independentes, o qual precisa ser estabelecido. (HABERMAS, 2007, p. 356-368)

Sendo assim, nota-se pelo todo exposto até então que os quadros da nacionalidade não foram fortemente alterados no transcurso das eras; pelo contrário, o de cidadania, sim, não mais vendo e requerendo a pessoa como elemento de um grupo limitado 
(família/Estado), mas como elemento da esfera planetária - ou, como prefere Habermas, como "cidadão do mundo" (Weltbürger).

\section{UM CONCEITO ATUAL PARA NACIONALIDADE}

Como detentora da soberania sobre seu território, atualmente se constata que a função estatal de delimitação dos nacionais é procedida por acepções puramente legais e provenientes do próprio Estado. Por essa maneira, o nacional vem a ser aquele a que o conjunto de normas de um país reconhece, de modo imparcial e direto, como sendo seu "filho", tendo "nascido" sob seu domínio; em outras palavras, é um descendente dessa "pátria", cujo termo bem e claramente se confunde com o ente familiar. Os traços culturais não são necessariamente expurgados dessa definição; antes, porém, passam pelo crivo da lei, de modo que, se há um vínculo entre a pessoa e a nação, esse vínculo se estriba numa série de preceitos cuja normatividade está sedimentada para que possa ser conclamada em favor da pessoa, de tal forma que - independendo se o fato jurídico que suscita a aquisição da nacionalidade seja o local de nascimento, de ascendência, de labor ou de moradia - as razões devem ser suficientemente válidas e eficazes em concurso à disposição legal, sem depender do beneplácito das pessoas circundantes (REZEK, 1978, p. 8). Isso posto, "o vínculo jurídico-político que une um indivíduo ao Estado Soberano em que ele é nacional” (KALICHSZTEIN, 2006, p. 119) é um "laço moral", mas também e fundamentalmente "um liame jurídico e político” (MARINHO apud DEL'OLMO, 2009, p. 225).**

Não desprezando a concepção sociológica da nacionalidade, i.e., a ligação do indivíduo a uma nação (DARDEAU DE CARVALHO, 1950, p. 08), mas concentrando por

\footnotetext{
** Outro não é o entendimento de Oscar Tenório (1970, p. 190-1): “[...] as regras sobre a nacionalidade, embora tenham às vezes às vezes efeitos internacionais, emanam da soberania de cada país. A liberdade para estabelecêlas é ampla; sofre apenas as restrições impostas pelo próprio Estado ao assinar tratados e convenções a respeito. Os interesses que resultam da coexistência das nações, através da atividade do comércio mundial em seus múltiplos aspectos, têm mostrado, entretanto, a necessidade de princípios gerais, ao menos sobre questões que, no presente, agravam a situação de um sem-número de pessoas, juridicamente anômalas, porque não se ligam a nenhum Estado, ou porque possuem mais de uma nacionalidade. [...] é conveniente que o Estado, ao elaborar a legislação sobre a nacionalidade, não olhe apenas os próprios interesses, mas se aperceba da existência de outras nações, da intensa comunicação entre os homens, a fimm de não proceder com egoísmo, como se cada país fosse hostil ao intercâmbio e estranho à interdependência". Na mesma linha: "O povo, formado pelo conjunto de nacionais, é elemento subjetivo do Estado, mas a fixação de regras para a determinação da nacionalidade foi e somente se desenvolveu a partir das revoluções liberais, que geraram a consequente afirmação da participação popular no poder. Assim, era necessário determinar quem era nacional, ou seja, quem era membro do povo e, por consequência, deveria participar, direta ou indiretamente, da condução dos destinos do Estado. Assim, a França foi o primeiro Estado, no pós-Revolução de 1789, a estabelecer regras constitucionais referentes à nacionalidade (Constituição de 1791, arts. $2^{\circ}$ a $6^{\circ}$ )" (RAMOS, 2007, p. 243-5).
} 
ora o estudo às questões jurídicas que tradicionalmente podem ser suscitadas, das várias posições doutrinárias que se possam tomar nos campos do Direito Constitucional e do Direito Internacional, ${ }^{\dagger \dagger}$ por mais percuciente, toma-se a de Clóvis Beviláqua (apud CAHALI, 1983, p. 03), que a entende como

[...] um vínculo público e pessoal, que liga o indivíduo a determinado país, sua pátria de origem ou de adoção, tornando-o parte integrante do povo desse país, e submetendo-o à autoridade e proteção da soberania, que nele impera. A nacionalidade é, assim, o estado de dependência, fonte de deveres, mas também de direitos, no qual se encontram os indivíduos em face de uma comunidade politicamente organizada.

Em contraste,

[...] estrangeiro é o não nacional, ou seja, aquele indivíduo que não satisfaz os pressupostos normativos do Estado para que se considere nacional. O Estado soberano, embora não esteja obrigado a consentir estrangeiros em seu território, mesmo em caráter temporário, a partir do momento em que nele os admite, passa a ter deveres para com os mesmos, decorrente de normas de direito internacional costumeiro, não se descuidando, contudo, da preservação dos interesses nacionais, à luz dos quais estabelecerá a condição jurídica do não-nacional (CARVALHO, 2007, p. 693-4).

Dito isso, mesmo sem esgotar o assunto, mas já com um ponto já consolidado, mister focar a leitura sobre o que se interpreta como cidadania, a fim de se encontrar os pontos de convergência e divergência.

\section{UMA IDEIA SOBRE CIDADANIA}

Não é incomum encontrar confusão entre os termos nacionalidade e cidadania, vendo-se inclusive (e tecnicamente) por muitos a segunda como decorrência direta da primeira (e.g., BONAVIDES, 1983, p. 68; DALLARI, 2001, p. 88; DEL'OLMO, 2001, p. 20; DEL'OLMO, 2010, p. 44; FERREIRA FILHO, 1989, p. 98-9; MALUF, 1986, p. 224-5; RAMELLA, 1978, p. 20; SALVETTI NETTO, 1982, p. 46). Embora para alguns ambos os termos sejam sinônimos, também os que o assim o fazem conseguem distinguir alguns pontos, como Bottomore (1996, p. 73-4):

Ideias de cidadania floresceram em diversos períodos históricos - na Grécia e na Roma antigas, nos burgos da Europa medieval, nas cidades do Renascimento. Mas a cidadania moderna, embora influenciada por essas concepções antigas, possui

${ }^{\dagger}$ ACCIOLY et al, 2010; ARAÚJO, 1995, p. 67; DEL'OLMO, 2009, p. 231; DOLINGER, 1997, p. 137; FERRANTE, 1984, p. 18; FINKELSTEIN, 2008, p. 9; MAZZUOLI, 2011, p. 665-9; MENDES et al, 2007, p. 679; PONTES DE MIRANDA, 1936, p. 17; PORTELA, 2011, p. 259; RAMELLA, 1978, p. 20; REZEK, 2010, p. 184-5; SILVA, 1997, p. 306-7; VARELLA, 2011, p. 176. 
um caráter próprio. Primeiro, a cidadania formal é hoje quase universalmente definida como a condição de membro de um estado-nação. Em segundo lugar, porém, a cidadania substantiva, definida como a posse de um corpo de [direitos] civis, políticos e especialmente sociais, tem-se tornado cada vez mais importante.

Há, pela leitura, uma diferença essencial: numa concepção, cidadania, sendo o laço entre pessoa e Estado, nada mais é que o próprio conceito de nacionalidade. Pouco ou nada, por conseguinte, há que se acrescentar ao estudado, podendo-se ponderar, que um vínculo desse quilate, desguarnecido de possibilidades de intervenção individual sobre o coletivo, esvazia-se ensimesmado. Prossegue-se, então, tendo em mente o que há pouco se denominou cidadania substantiva à cidadania mesmo, i.e., um conjunto de direitos atribuídos à pessoa e que dela se tornam imanentes.

Não é temerário ousar referir que a confusão (e a separação) dos conceitos tem como maior aliada a francesa Declaração dos Direitos do Homem e do Cidadão, de 1789. Nela, não se fazendo distinção clara entre quem é ou não cidadão, seu terceiro artigo preceitua que "le principe de toute Souveraineté réside essentiellement dans la Nation. Nul corps, nul individu ne peut exercer d'autorité qui n'en émane expressément", e no sexto, a despeito da lei ser a expressão da vontade geral, "tous les Citoyens ont droit de concourir personnellement, ou par leurs Représentants, à sa formation”, e que "tous les Citoyens étant égaux à ses yeux sont également admissibles à toutes dignités, places et emplois publics [...]" - ou seja, são os cidadãos, componentes da nação, que concorrem para a composição do poder, inobstante serem todos os homens iguais em direitos (art. $1^{\circ}$ ), cabendo-lhes a liberdade, a propriedade, a segurança e a resistência à opressão (inclusive de quem não seja cidadão). Eis, portanto, direitos civis e elementares distribuídos (ou, ao menos, apregoados) a todos, mas os direitos políticos apenas fazendo parte do rol de possibilidades dos cidadãos, quer dizer, dos nacionais. Todavia, uma simples anunciação de direitos, anunciando possibilidades, mas não dotando os indivíduos de reais condições de os fruírem, como se disse, torna a cidadania um mero legitimador de estamentos, não sendo então um poder, mas uma vaga possibilidade.

T. H. Marshall (1967) faz a leitura do instituto tomando como ponto de referência três premissas que se foram agregando ao correr dos tempos no curso da legislação britânica - quais sejam, os direitos civis, os direitos políticos e os direitos sociais. Todavia, vale referir, essas "gerações" de direitos não surgiram cristalizados ou irrestritos, mas se disseminaram conforme a "possibilidade" de adequação da parcela do povo ao que se 
propunha ao espaço - e nisso, oportuno lembrar, a título de ilustração, o voto censitário, que foi inclusive realidade brasileira durante a vigência da Constituição brasileira de 1824, e que restringia a capacidade eleitoral ativa e passiva. Como contextualiza Fernanda Savian Rodrigues (2011, p. 19):

Num lapso temporal flexível, que abarca desde o século XVIII até o século XX, direitos inicialmente civis, voltados ao exercício das liberdades, somaram-se a direitos políticos, relativos à participação política, e, por fim, agregaram-se a direitos sociais, correspondentes à aquisição de um bem-estar social mínimo pelos integrantes da sociedade. Contudo, os direitos descritos conferiam aos seus titulares um status que, a despeito de sua ampliação material gradativa, não se estendia a toda população. Em suma, há que se estabelecer uma distinção primária entre conteúdo e titularidade/distribuição de direitos, cuja latência permeará o desenvolvimento da ideia de cidadania, num ou noutro sentido.

No entanto,

[...], verifica-se que os direitos de cidadania vinculavam-se, desde sua origem, a uma ordem nacional, porquanto no período medieval encontravam-se, assim como as instituições, fundidos num todo indiferenciado, não havendo, nesse contexto, um princípio de igualdade para contrastar com a desigualdade de classes definidas pelo status, operando, ademais, localmente. Logo, a reconstituição dessa história parte de um duplo processo, qual seja de fusão geográfica e de separação funcional (MARSHALL, 1967, p. 62).

E também como o próprio Marshall (1967, p. 79) disse,

\begin{abstract}
Não obstante, a verdade é que a cidadania, mesmo em suas formas iniciais, constituiu um princípio de igualdade, e que, durante aquele período, era uma instituição em desenvolvimento. Começando do ponto no qual todos os homens eram livres, em teoria, capazes de gozar de direitos, a cidadania se desenvolveu pelo enriquecimento do conjunto de direitos que eram capazes de gozar.
\end{abstract}

Entretanto, até então não era concebível discutir e exigir peremptoriamente o acesso a direitos em qualquer espaço estatal, uma vez que o direito das coletividades decorria justamente do reconhecimento individual conferido ao Estado, que respondia em via de retorno. Em outras palavras, o direito da pessoa nada mais era que o direito que o Estado conferia a ela, e isso fazia porque ele, o poderoso Leviatã, recebeu da pessoa mesmo. Foi com o advento do reconhecimento dos direitos humanos, colocando a pessoa ensimesmada no cerne do Direito (quer no plano interno, quer na esfera internacional) e retirando do poderio estatal a capacidade de dispor impunemente dos indivíduos sob sua guarida (mormente como se viu nos sanguinolentos espetáculos de horror produzidos durante a Segunda Grande Guerra), que se rediscutiu ferozmente a posição de um frente ao outro (CANÇADO TRINDADE, 2008), banindo-se de vez a aligeância e pondo a humanidade na 
discussão do Direito das Gentes, reconhecendo textualmente, já desde o discurso de Franklin Roosevelt, as lacônicas freedom from fear, freedom from want, freedom of thinking, freedom of worship.

Mazzuoli (2011, p. 420-6) vê, em virtude do avanço na História, que o homem tornase veramente sujeito de Direito Internacional ${ }^{\sharp}$, devendo sua condição ser respeitada no espaço global e podendo fazer frente, se for o caso, inclusive perante países e organizações interestatais. Não surge isso de modo gratuito: deve ele saber que pode e deve agir, nas palavras da Declaração Universal dos Direitos Humanos, tendo em vista "que o reconhecimento da dignidade inerente a todos os membros da família humana e de seus direitos iguais e inalienáveis é o fundamento da liberdade, da justiça e da paz no mundo".

E é a premência e a exigência pós-moderna de um mundo de paz, apregoada pela Organização das Nações Unidas, aliada a uma situação de multiculturalidade e de multipolaridade econômico-social, que acabam por fundar e estabelecer uma nova abordagem à cidadania, apresentando-a enquanto ressignificação do espaço plural. Pluralizar a discussão não se sinonimiza à pura igualdade no debate, conquanto abra margem a considerar diferenças e, mesmo assim, trazê-las sem desforrá-las de legitimidade para tal - “[...] a expressão direitos iguais significa não somente direito a tratamento igual, mas também direito a ser tratado como igual, apesar das diferenças" (VIEIRA, 2001, p. 229). Nesse modo consoante,

[...] cidadania não é somente exercício de direitos, vinculada a uma instituição histórica; antes, ela se constitui numa maneira de se fazer a emancipação do sujeito humano que é de natureza política, social, cultural e ambiental, resultando numa forma política de viver civilizado (BERTASO, 2004, p. 292).

Sob esse prisma, não há mais como se falar na cidadania enquanto concessão do Estado; transmuta-se, então, em argumento de legitimidade ao convívio do coletivo. Cidadanizar, em um sentido amplo, é movimento inclusivo, integrador, não somente legando opções de capacidade, mas tornando factíveis hipóteses que avaliem, ponderem e agreguem, tanto quanto seja possível, as individualidades (e, como tal, singularidades) em um campo de convergência, no intuito de proporcionar ao grupo formado uma condição de subsistência geral, obrigatoriamente não olhando o todo - leia-se mormente o Estado maior que as parcelas que o compõe.

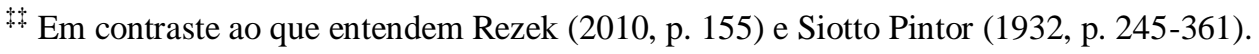


Por essa vereda, insoslaiável é a ideia de democracia: recordada hodiernamente pelo conceito de Abraham Lincoln enquanto "governo do povo, pelo povo, para o povo", Barry Holden (1996, p. 179-82) a conceitua enquanto "um sistema político no qual o povo inteiro toma, e tem o direito de tomar, as decisões básicas determinantes a respeito de questões importantes de políticas públicas". Não discutindo aqui profundas questões de legitimidade dos partícipes a serem incluídos, entretanto contemplando a cidadania enquanto escopo acolhedor de pluralidades, segue-se silogisticamente que uma democracia cidadã, ainda que longe de proferir decisões placitadas, é uma forma de regência que encampa (ou, ao menos, esforça-se para tal) a totalidade de atores e matizes, colocando à mesa suas preferências e antagonismos, visando ao bem-estar de todos.

\section{CONCLUSÃO}

Mesmo em poucas linhas, pode-se concluir que cidadania e nacionalidade não são conceitos obrigatoriamente vinculados, e, se são, não o fazem subordinadamente. Uma vez que a cidadania é um espaço comum para discussão entre os indivíduos, não cabe mais dizer, como o foi outrora, que a nação antecede aos cidadãos, limitando-os em suas fronteiras (nesse sentido, Bredariol; Liszt, 1998). As relações entre países, tal qual as relações em geral, estão paulatinamente sendo mais alargadas e se mostram diuturnamente mais substanciais que as próprias barreiras às quais se lhes era imposta pela soberania (como já discutiu Santos, 2009, p. 56), de forma que, ao final das contas, o que se apresenta é a constatação feita por Morin (2003, p. 54-5): "não se pode tornar o indivíduo absoluto e fazer dele o fim supremo desse circuito [indivíduo/sociedade/espécie]; tampouco se pode fazê-lo com a sociedade ou a espécie", pois "a complexidade humana não poderia ser compreendida dissociada dos elementos que a constituem".

Vê-se, em aplicação, que o desenvolvimento da potencialidade do Estado, ente político da nação sociológica, é ao mesmo tempo antecedente e consequente ao cidadão/indivíduo; ambos são o ponto de partida, e há uma cumplicidade para que sejam pontos de chegada no intuito de desenvolver a multiplicidades de condições da pessoa enquanto singularidade e pluralidade. São, em suma, o que está posto e o que conduzem ao devir, ou, como disse filosófica e poeticamente Eduardo Prado de Mendonça (1984, p. 73), a solução em busca do problema. 
Pelo arcabouço estudado, refletindo-se sobre a condição social atual, nada impede, assim, que nacionais sejam cidadãos; muito pelo contrário, reconhece-se à população de território delimitado os direitos inerentes à participação ativa em sua sociedade, o que é conveniente e necessário à uma comunidade de pessoas. Reduzir a cidadania, contudo, à simples consequência de chancela pública sobre indivíduos é rebaixar a pessoa do status de partícipe a mera engrenagem, coisificando-o enquanto ferramenta do poder estatal, desconsiderando a razão de ser do próprio Estado, que, por qualquer viés ideológico, busca o bem-estar do grupo ao qual se destina. E por assim ser, nacionalidade e cidadania, apesar de caminharem pari passu, não se confundem, mas também não podem destoar por completo.

\section{REFERENCIAS}

ACCIOLY, Hildebrando; CASELLA, Paulo Borba; SILVA, G. E. do Nascimento e.

Manual de direito internacional público. 18. ed. atual. São Paulo: Saraiva, 2010.

ARAÚJO, Luís Ivani de Amorim. Direito internacional público. 9. Ed. Rio de Janeiro: Forense, 1995.

ARISTÓTELES. Ética a Nicômaco. São Paulo: Martin Claret, 2003.

BERTASO, João Martins. Cidadania e direitos humanos: um trânsito para a solidariedade. Florianópolis: Tese (Doutorado em Direito), Coordenação de Pós-Graduação em Direito, Universidade Federal de Santa Catarina, 2004.

BÍBLIA Sagrada. Nova Versão Internacional. São Paulo: Sociedade Bíblica Internacional, 2000.

BODIN, Jean. BERMEJO CABRERO, José Luis (Ed.). Los seis libros de la republica. Madrid: Centro Estud. Constitucionales, 1992. 2 v. (Clásicos del Pensamiento Político y Constitucional Español; 20).

BONAVIDES, Paulo. Ciência política. Rio de Janeiro: Forense, 1983.

BOTTOMORE, Tom. Cidadania [verbete]. In: BOTTOMORE, Tom; OUTHWAITE, William (ed.). Dicionário do Pensamento Social do Século XX. Rio de Janeiro: Jorge Zahar, 1996.

BREDARIOL, Celso; VIEIRA, Liszt. Cidadania e política ambiental. Rio de Janeiro: Record, 1998.

CAHALI, Yussef Said. Estatuto do estrangeiro. São Paulo: Saraiva, 1983. 
CANÇADO TRINDADE, Antônio Augusto. Evolution du droit international au droit des gens: l'accès des individus à la justice internationale - le regard d'un juge. Paris: A Pedone, 2008.

CARVALHO, Kildare Gonçalves. Direito constitucional. 13. ed. rev. atual. e ampl. Belo Horizonte: Del Rey, 2007.

COUlANGES, Fustel de. A cidade antiga. 2. ed, 4. reimp. São Paulo: Martin Claret, 2008.

DAL RI JÚNIOR, Arno. Evolução histórica e fundamentos político-jurídicos da cidadania. In: DAL RI JÚNIOR, Arno; OLIVEIRA, Odete Maria de. Cidadania e nacionalidade: efeitos e perspectivas nacionais - regionais - globais. 2. ed. Ijuí: Unijuí, 2003.

DALLARI, Dalmo de Abreu. Elementos de Teoria Geral do Estado. 22 ed. São Paulo: Saraiva, 2001.

DARDEAU DE CARVALHO, A. Nacionalidade e cidadania. Rio de Janeiro/São Paulo: Freitas Bastos, 1950.

DEL'OLMO, Florisbal de Souza. Curso de direito internacional privado. 8.ed. rev. atual. Rio de Janeiro: Forense, 2010.

Janeiro: Forense, 2009.

Curso de direito internacional público. 4. ed. Rio de

. O Mercosul e a nacionalidade: estudo à luz do direito

internacional. Rio de Janeiro: Forense, 2001.

DOLINGER, Jacob. Direito internacional privado (parte geral). 5. ed. Rio de Janeiro: Renovar, 1997.

DURKHEIM, Émile. Da divisão do trabalho social. 2.ed. São Paulo: Martins Fontes, 1999.

FARIA, Ernesto. Dicionário latino-português. 6. ed. Rio de Janeiro: FAE, 1988.

FERRANTE, Miguel Jeronymo. Nacionalidade: brasileiros natos e naturalizados. 2. ed. São Paulo: Saraiva, 1984.

FERREIRA FILHO, Manoel Gonçalves. Curso de direito constitucional. 17.ed. rev. atual. São Paulo: Saraiva, 1989.

FINKELSTEIN, Cláudio. Direito internacional. São Paulo: Atlas, 2008 (Leituras Jurídicas).

HABERMAS, Jürgen. Entre naturalismo e religião: estudos filosóficos. Rio de Janeiro: Tempo Filosófico, 2007.

HOBBES, Thomas. Do cidadão. 2. ed. São Paulo: Martins Fontes, 1998. 
HOLDEN, Barry. Democracia [verbete]. In: In: BOTTOMORE, Tom; OUTHWAITE, William (ed.). Dicionário do Pensamento Social do Século XX. Rio de Janeiro: Jorge Zahar, 1996.

KALICHSZTEIN, Juliana. Nacionalidade. In: CHAPARRO, Verônica Zarate; FERREIRA JUNIOR, Lier Pires. (coord.). Curso de direito internacional privado. Rio de Janeiro: Freitas Bastos, 2006.

KANT, Immanuel. À paz perpétua. Porto Alegre: L\&PM, 2010 (L\&PM POCKET PLUS).

LISSNER, Ivar. Os Césares. Belo Horizonte: Itatiaia, 1985, (Descoberta do Mundo, 29).

MALUF, Sahid. Teoria geral do Estado. 17.ed. rev. atual. São Paulo: Sugestões Literárias, 1986.

MARSHALL, T. H. Cidadania, classe social e status. Rio de Janeiro: Zahar, 1967.

MAZZUOLI, Valerio de Oliveira. Curso de direito internacional público. 5. ed., rev., atual. e ampl. São Paulo: RT, 2011.

MENDES, Gilmar Ferreira et al. Curso de direito constitucional. São Paulo: Saraiva, 2007.

MENDONÇA, Eduardo Prado de. O mundo precisa de filosofia. 7.ed. Rio de Janeiro: Agir, 1984.

MORIN, Edgar. Os sete saberes necessários à educação do futuro. 8. ed. Trad. Catarina Eleonora F. da Silva e Jeanne Savaya. São Paulo: Cortez, Brasília: UNESCO, 2003.

PONTES DE MIRANDA. Nacionalidade de origem e naturalização no direito brasileiro. Rio de Janeiro: Coelho Branco Filho, 1936.

PUFENDORF, Samuel. Of the Law of Nature and Nations. Oxford: [s.e], 1703.

Disponível em: http://encurtador.com.br/cfnz9. Acesso em: 10 jan. 2021.

RAMELLA, Pablo. Nacionalidad y ciudadanía. Buenos Aires: Depalma, 1978.

RAMOS, André de Carvalho. Nacionalidade [verbete]. In: DIMOULIS, Dimitri (coord.). Dicionário brasileiro de direito constitucional. São Paulo: Saraiva, 2007.

REZEK, José Francisco. A nacionalidade à luz da obra de Pontes de Miranda. In: Revista Forense. Rio de Janeiro, a. 74, fasc. 901-903, nº 263, p. 7-15, jul./set. 1978.

São Paulo: Saraiva, 2010.

Direito internacional público: curso elementar. 12. ed. rev. atual.

RODRIGUES, Fernanda Savian. Cidadania, direitos humanos e emancipação: uma perspectiva em construção. Dissertação (Mestrado em Direito), Departamento de Ciências Sociais Aplicadas, Universidade Regional Integrada do Alto Uruguai e das Missões, Santo Ângelo, 2011. 
ROUSSEAU, Jean-Jacques. O contrato social. São Paulo: Formar, 1978.

SALVETTI NETTO, Pedro. Curso de teoria do Estado. São Paulo: Saraiva, 1982.

SANTOS, Boaventura de Souza. Um discurso sobre as ciências. 6. ed. São Paulo: Cortez, 2009.

SIÈYES, Emmanuel Joseph. A constituinte burguesa - que é o terceiro estado? Rio de Janeiro: Liber Juris, 1986.

SILVA, José Afonso. Curso de direito constitucional positivo. 13. ed. rev. São Paulo: Malheiros, 1997.

SIOTTO PINTOR, Manfredi. Les sujets du droit international autres que les États (Volume 41). In: Collected Courses of the Hague Academy of International Law. Disponível em: http://dx.doi.org/10.1163/1875-8096 pplrdc A9789028607828 03. Acesso em: 09 jan. 2021.

SOUZA JÚNIOR, Cezar Saldanha. O Tribunal Constitucional como Poder: uma nova teoria da divisão dos poderes. São Paulo: Memória Jurídica, 2002.

TENÓRIO, Oscar. Direito internacional privado. 10. ed. Rio de Janeiro: Freitas Bastos, 1970.

VARELLA, Marcelo Dias. Direito internacional público. $3^{\text {a }}$ ed. São Paulo: Saraiva, 2011, p. 193.

VIEIRA, Liszt. Os argonautas da cidadania: a sociedade civil na globalização. Rio de Janeiro: Record, 2001. 